\title{
Reproductive risk factors for endometrial cancer among Polish
}

\section{women}

\section{LA Brinton*, , LC Sakoda', J Lissowska ${ }^{2}$, ME Sherman', N Chatterjee ${ }^{3}$, B Peplonska ${ }^{4}$, N Szeszenia-Dabrowska ${ }^{4}$, W Zatonski ${ }^{2}$ and M Garcia-Closas'}

'Hormonal and Reproductive Epidemiology Branch, Division of Cancer Epidemiology and Genetics, National Cancer Institute, 6120 Executive Blvd., Suite 550, Rockville, MD 20852-7234, USA; '2Department of Cancer Epidemiology and Prevention, Cancer Center and M. Sklodowska-Curie Institute of Oncology, W.K. Roentgena 5, Warsaw 02-78I, Poland; ${ }^{3}$ Biostatistics Branch, Division of Cancer Epidemiology and Genetics, National Cancer Institute, Rockville, MD 20852, USA; ${ }^{4}$ Department of Occupational and Environmental Epidemiology, Nofer Institute of Occupational Medicine, Lodz, Poland

We conducted a population-based case-control study of reproductive factors in Warsaw and Lódź, Poland, in 55। incident endometrial cancer cases and 1925 controls. The reproductive variable most strongly related to risk was multiparity, with subjects with three or more births having a 70\% lower risk than the nulliparous women. The reduced risk was particularly strong below 55 years of age. Subjects with older ages at a first birth were also at reduced risk even after adjustment for number of births. Ages at last birth or intervals since last birth were not strongly related to risk. Spontaneous abortions were unrelated to risk, but induced abortions were associated with slight risk increases (odds ratios $=1.28,95 \%$ confidence intervals $0.8-2.1$ for $3+$ vs no abortions). The absence of effects on risk of later ages at, or short intervals since, a last birth fails to support the view that endometrial cancer is influenced by mechanical clearance of initiated cells. Alternative explanations for reproductive effects should be sought, including alterations in endogenous hormones.

British Journal of Cancer (2007) 96, I450- |456. doi:I0.1038/sj.bjc.660373 I www.bjcancer.com

Published online 10 April 2007

(c) 2007 Cancer Research UK

Keywords: endometrial cancer; reproduction; risk; abortion; breastfeeding

Nulliparous women are known to be at an increased risk of endometrial cancer, but effects of other reproductive factors remain less defined. Inverse associations with later ages at a first birth have been demonstrated in some studies (Kvale et al, 1988; Albrektsen et al, 1995; Parslov et al, 2000; Wernli et al, 2006), although not in all of them (Lesko et al, 1991; Parazzini et al, 1991, 1998; Shu et al, 1991; Brinton et al, 1992; McPherson et al, 1996; Lambe et al, 1999). More recently, studies have suggested that risk may decrease with later ages at a last birth (Kvale et al, 1988, 1991; Lesko et al, 1991; Parazzini et al, 1991, 1998; Lambe et al, 1999). This may reflect the fact that late ages at a last birth tend to be associated with shorter intervals since last births (Albrektsen et al, 1995; Parazzini et al, 1998), prompting the suggestion that premalignant or initiated cells may be mechanically cleared during the birth process (Kvale et al, 1991; Lambe et al, 1999). Alternatively, women who are unable to give birth at later ages may be at high risk given anovulatory menstrual cycles and low associated progesterone levels (Kaaks et al, 2002).

Effects of other reproductive factors on endometrial cancer also remain unresolved. At least one study has suggested elevated risks among women with abortions late in reproductive life that are not followed by a subsequent term pregnancy (McPherson et al, 1996). Effects of breastfeeding on risk also remain controversial (Brinton

*Correspondence: Dr LA Brinton; E-mail: brinton@nih.gov Received 30 January 2007; revised 7 March 2007; accepted 14 March 2007; published online 10 April 2007 et al, 1992; Rosenblatt and Thomas, 1995; Salazar-Martinez et al, 1999; Newcomb and Trentham-Dietz, 2000).

In many of the previous investigations, reproductive relationships may have been obscured by high rates of usage of exogenous hormones. In a recently completed study in Poland, where rates of exogenous hormone use are low, we had the opportunity to clarify a variety of unresolved reproductive issues related to endometrial carcinogenesis.

\section{MATERIALS AND METHODS}

\section{Study subjects and data collection procedures}

Eligible cases for this population-based case-control study consisted of residents of Warsaw and Lódź, Poland, ages 20-74 years, with incident endometrial cancer diagnosed between June 1, 2001 and December 30, 2003. Cases were recruited through a rapid identification system organised at five participating hospitals, consisting of, in Warsaw, the Cancer Center, M. Curie Sklodowska Institute of Oncology Institute, and Polish Oncological Foundation, and in Lodz the Dr Madurowicz Memorial Hospital and Polish Mother's Health Memorial Hospital. These hospitals covered about $85 \%$ of all cases diagnosed in the two cities. Information from the Cancer Registries in Warsaw and Lodz was used to identify cases that were missed by the rapid identification system.

The Polish Electronic System (PESEL), a database with demographic information from all residents of Poland, was used to select controls. A complementary breast cancer study, initiated 
in January 2000, in which controls were randomly selected according to the anticipated age distribution (in 5 year categories) of breast cancer cases in each city provided a source for controls from the beginning of the endometrial cancer study until the end of the breast study (September 30, 2003). These controls were supplemented with additional subjects who were specifically selected for the endometrial cancer cases. One control per cancer case was selected during the breast cancer study, with two controls per case after this time. Eligible controls had neither a history of breast or endometrial cancer at enrolment.

After obtaining signed informed consent forms approved by the National Cancer Institute and local Institutional Review Boards (IRB), personal interviews were conducted using a questionnaire on demographic and reproductive factors, contraceptive behaviour, use of exogenous hormones, physical activity, passive and active cigarette smoking, occupational history, diet, alcohol use, first-degree family history of breast and ovarian cancer, medical and screening history, prenatal exposures and developmental history.

Of the 694 eligible cases and 2843 eligible controls, 551 (79.4\%) and $1925(67.7 \%)$, respectively, agreed to complete an interview. The primary reason for non-response was refusal, relevant to 106 $(15.3 \%)$ of the eligible cases and $705(24.8 \%)$ of the controls. The median length of the interview was $85 \mathrm{~min}$, and the overall quality as rated by the interviewers was identical for the cases and controls, with $48.1 \%$ rated high quality, $49.1 \%$ generally reliable, $2.3 \%$ unreliable, and $0.5 \%$ unrated. The median time from case diagnosis to interview was 69.0 days and the median time from control selection to interview was 19.0 days. Medical records of endometrial cancer patients were reviewed for diagnostic and treatment details.

Information on all prior pregnancies was collected, including outcomes (livebirth, stillbirth, miscarriage, abortion, other), gestational lengths (in weeks or months), and dates each pregnancy ended. For livebirths, subjects were asked whether they had breastfed the baby and for how long. Subjects were also asked if they had ever tried to become pregnant for two straight years without successful conception and whether they had ever visited a doctor, clinic or hospital because of difficulty in becoming pregnant. If relevant, they were asked when they first sought advice and whether they were given any medication or hormones to help in getting pregnant.

\section{Statistical analysis}

Unconditional logistic regression analysis was used to estimate adjusted odds ratios (OR) and associated $95 \%$ confidence intervals (CI). In order to examine the independent effects of correlated reproductive factors, we used the approach described by Heuch and others (Heuch et al, 1999), in which regression models were constructed using data from nulliparous and parous women.

\section{RESULTS}

Information pertaining to the distribution of risk factors among the study participants is shown in Table 1 . The mean age of the cases was 60.7 years, compared with 56.2 years among the controls. The majority of the study subjects derived from Warsaw. Cases tended to be somewhat better educated, more often menopausal, and to have earlier ages at menarche than controls. Although rates of usage were low, hormone replacement therapy (primarily combined oestrogen-progestin therapy) was more common among cases than controls, whereas the reverse was true regarding oral contraceptives. Cases were heavier than controls and were less often cigarette smokers, but there were no substantial differences between the two groups with respect to overall usage of alcoholic beverages.
Table I Distribution of non-reproductive risk factors among study participants

\begin{tabular}{|c|c|c|c|c|}
\hline \multirow[b]{2}{*}{ Study variables } & \multicolumn{2}{|c|}{$\begin{array}{c}\text { Cases } \\
(n=55 I)\end{array}$} & \multicolumn{2}{|c|}{$\begin{array}{l}\text { Controls } \\
(n=1925)\end{array}$} \\
\hline & Number & Percent & Number & Percent \\
\hline \multicolumn{5}{|l|}{ Age, years } \\
\hline$<55$ & 133 & 24.1 & 889 & 46.2 \\
\hline $55-64$ & 206 & 37.4 & 547 & 28.4 \\
\hline $65+$ & 212 & 38.5 & 489 & 25.4 \\
\hline \multicolumn{5}{|l|}{ Study site } \\
\hline Warsaw & 393 & 71.3 & 1316 & 68.4 \\
\hline Lodz & 158 & 28.7 & 609 & 31.6 \\
\hline \multicolumn{5}{|l|}{ Years of education } \\
\hline$<$ High school & 188 & 34.1 & 727 & 37.8 \\
\hline High school & 207 & 37.6 & 728 & 37.8 \\
\hline $\begin{array}{l}\text { Some college or } \\
\text { professional training }\end{array}$ & 152 & 27.6 & 460 & 23.9 \\
\hline \multicolumn{5}{|l|}{ Age at menarche, years } \\
\hline$<13$ & 155 & 28.1 & 412 & 21.4 \\
\hline 13 & 138 & 25.0 & 428 & 22.2 \\
\hline 14 & 135 & 24.5 & 546 & 28.4 \\
\hline $15+$ & 120 & 21.8 & 513 & 26.7 \\
\hline \multicolumn{5}{|l|}{ Regular menstrual cycles } \\
\hline Yes & 470 & 85.3 & 1648 & 85.6 \\
\hline No & 81 & 14.7 & 277 & 14.4 \\
\hline \multicolumn{5}{|l|}{ Menopause status } \\
\hline Premenopausal & 93 & 16.9 & 623 & 32.4 \\
\hline Postmenopausal & 416 & 75.5 & 1199 & 62.3 \\
\hline \multicolumn{5}{|c|}{ Use of oral contraceptives } \\
\hline No & 520 & 94.4 & 1703 & 88.5 \\
\hline Yes & 28 & 5.1 & 199 & 10.3 \\
\hline \multicolumn{5}{|c|}{$\begin{array}{l}\text { Use of hormone replacement } \\
\text { therapy }\end{array}$} \\
\hline No & 404 & 73.3 & 1469 & 76.3 \\
\hline Yes & 140 & 25.4 & 431 & 22.4 \\
\hline \multicolumn{5}{|l|}{ Cigarette smoking } \\
\hline Non-smoker & 358 & 65.0 & 898 & 46.6 \\
\hline Past & 92 & 16.7 & 356 & 18.5 \\
\hline Current & 101 & 18.3 & 671 & 34.9 \\
\hline \multicolumn{5}{|c|}{ Alcohol intake, drinks/week } \\
\hline None & 412 & 74.8 & 1295 & 67.3 \\
\hline$<2$ & 72 & 13.1 & 296 & 15.4 \\
\hline $2-<3$ & 19 & 3.4 & 88 & 4.6 \\
\hline $3-<4$ & 12 & 2.2 & 51 & 2.6 \\
\hline$\geqslant 4$ & 18 & 3.3 & 140 & 7.3 \\
\hline \multicolumn{5}{|l|}{$\begin{array}{l}\text { Recent body mass index, } \\
\mathrm{kg} \mathrm{m}^{-2}\end{array}$} \\
\hline$<23.05$ & 81 & 14.7 & 461 & 23.9 \\
\hline $23.05-25.94$ & 120 & 21.8 & 476 & 24.7 \\
\hline $25.95-29.17$ & 136 & 24.7 & 473 & 24.6 \\
\hline $29.18+$ & 208 & 37.7 & 469 & 24.4 \\
\hline
\end{tabular}

Missings excluded from presentation, but included in denominator for calculation of above percentages. Numbers of missing for cases vs controls were as follows: age $(0,0)$, years of education $(4,10)$, age at menarche $(3,26)$, menopausal status $(7,1 \mid 2)$, use of oral contraceptives $(3,23)$, use of hormone replacement therapy $(7,25)$, cigarette smoking $(0,0)$, alcohol intake $(18,55)$, recent body mass index $(6,46)$.

A significantly decreased risk was associated with parity $\left(\mathrm{OR}_{\mathrm{adj}}\right.$ for parous $v s$ nulliparous $=0.51,95 \%$ CI $0.4-0.7$ ) (Table 2). In addition, risks decreased with increasing numbers of pregnancies (data not shown) and numbers of full-term births, with a slightly 
Table 2 Relationships of reproductive factors to endometrial cancer risk

\begin{tabular}{|c|c|c|c|c|}
\hline Risk factors & $\begin{array}{l}\text { No. of cases } \\
\quad(n=55 I)\end{array}$ & $\begin{array}{l}\text { No. of controls } \\
\quad(n=1925)\end{array}$ & $\begin{array}{c}\text { Age and site-adjusted } \\
\text { OR }(95 \% \mathrm{Cl})\end{array}$ & $\begin{array}{l}\text { Fully adjusted } \\
\text { OR }(95 \% \mathrm{CI})^{\mathrm{a}}\end{array}$ \\
\hline \multicolumn{5}{|c|}{ Ever had a full-term birth } \\
\hline No & 102 & 218 & 1.00 & 1.00 \\
\hline \multicolumn{5}{|c|}{ Number of full-term births } \\
\hline 0 & 102 & 218 & 1.00 & 1.00 \\
\hline $3+$ & 53 & 313 & $0.31(0.2-0.5)$ & $0.30(0.2-0.4)$ \\
\hline & & & $P($ trend $)<0.0001$ & $P($ trend $)<0.0001$ \\
\hline \multicolumn{5}{|c|}{ Number of spontaneous abortions ${ }^{b}$} \\
\hline 0 & 367 & 1348 & 1.00 & 1.00 \\
\hline I & 81 & 327 & $0.88(0.7-1.2)$ & $0.84(0.6-1.1)$ \\
\hline $2+$ & 34 & 98 & $1.23(0.8-1.9)$ & $1.10(0.7-1.7)$ \\
\hline 2 & 58 & 164 & $1.32(0.9-1.8)$ & $1.31(0.9-1.9)$ \\
\hline $3+$ & 30 & 75 & $1.33(0.8-2.1)$ & $1.28(0.8-2.1)$ \\
\hline & & & $P($ trend $)=0.02$ & $P($ trend $)=0.05$ \\
\hline \multicolumn{5}{|c|}{ Ever problem with infertility } \\
\hline No & 498 & 1769 & 1.00 & 1.00 \\
\hline Yes & 52 & 150 & $1.33(0.9-1.9)$ & $1.03(0.7-1.5)$ \\
\hline Unknown & I & 6 & & \\
\hline
\end{tabular}

${ }^{a}$ Fully adjusted model includes age, site, years of education, age at menarche, number of full-term births, ever use of oral contraceptives, ever use of oral hormones, ever smoking recent body mass index. ${ }^{b}$ Restricted to gravid women.

stronger relationship seen with the latter variable. The largest reduction in risk was for the initial birth $\left(\mathrm{OR}_{\mathrm{adj}}=0.60,95 \% \mathrm{CI}\right.$ 0.4-0.8 for 1 birth vs 0 birth), although subsequent births were associated with continued reductions in risk $\left(\mathrm{OR}_{\mathrm{adj}}=0.30,0.2-0.4\right.$ for 3 or more $v s 0$ births).

Among gravid women, a history of any spontaneous abortion was unrelated to risk, but there was a slightly increased risk for women who reported an induced abortion. However, there was no evidence that risk increased linearly with number of induced abortions, the risk for those with three or more induced abortions being similar to that with only one abortion (respective ORs of 1.28 $(0.8-2.1)$ and $1.31(1.0-1.7))$. The risks associated with a history of induced abortion did not differ significantly by whether women were parous or nulliparous.

In contrast to the other reproductive parameters, a history of infertility (defined as the inability to get pregnant after trying to conceive for 2 years or longer) was only marginally related to risk and this association entirely disappeared after adjustment for other risk factors. A history of infertility was also not related to risk when defined more specifically according to whether physician advice had ever been sought or treatment received. Using various definitions, infertility was also not associated with risk when examined specifically among nulliparous women.

For consistency with most previous published analyses that have attempted to distinguish effects of correlated reproductive risk factors, further analyses focused on parous women (Table 3). In initial analyses, age at first birth did not appear related to risk, but after adjustment for other factors a trend of decreasing risk with increasing ages emerged. This showed that subjects with a first birth at 30 or later had an OR of 0.75 (95\% CI $0.5-1.2)$ compared with those with a first birth before 20. Age at last birth appeared initially to be inversely related to risk, a trend that did not persist after adjustment for other factors. Interval since last birth was not related to endometrial cancer risk in any linear fashion before adjustment for other risk factors, but after adjustment for other factors (including parity, which was the major confounder), there was some evidence of increased risk with shorter intervals since last birth - with subjects whose last birth occurred within the last 20 years being at a nonsignificantly increased risk $(\mathrm{OR}=1.52,95 \% \mathrm{CI}$ $0.8-2.9$ ) compared with those whose last birth occurred 40 or more years before diagnosis. When we further divided this group into those who had given birth within 15-20 years $v s$ within 15 years, there were discrepant risks, being, respectively, $1.78(0.9-3.4) v s$ $0.81(0.3-2.0)$. However, this latter risk was based on only 10 cases and 220 controls. Among parous women, extended breastfeeding (24 or more months) appeared initially to be associated with a significant decrease in risk, but this relationship was attenuated after adjustment for a variety of other factors, including parity.

We also used a modelling approach (Heuch et al., 1999), which allowed us to simultaneously account for various time-related aspects of reproduction, including ages at first and last delivery (with this latter variable restricted to those with two or more births), and intervals since last birth (Table 4). Despite the different analytic approach, most results were similar to those derived from more traditional modelling approaches. Notably, parity persisted as the primary predictor of risk, with subjects with three or more births being at a $70 \%$ lower risk than nulliparous women (95\% CI $0.2-0.5)$. Age at first birth also continued to show inverse associations with risk $(\mathrm{OR}=0.69$ for subjects $30+v$ s $<20$ ), whereas age at last birth was unrelated to risk. However, in contrast to our previous analyses, which suggested a possible increase in risk with years since last birth, these additional analyses showed no association with risk.

We also examined risks according to varying ages at diagnosis $(<55,55-65,65+$ years $)$. As trends were very similar for the women 55-65 and those over 65, we combined these two groups 
Table 3 Relationships of additional reproductive factors to endometrial cancer risk among parous women

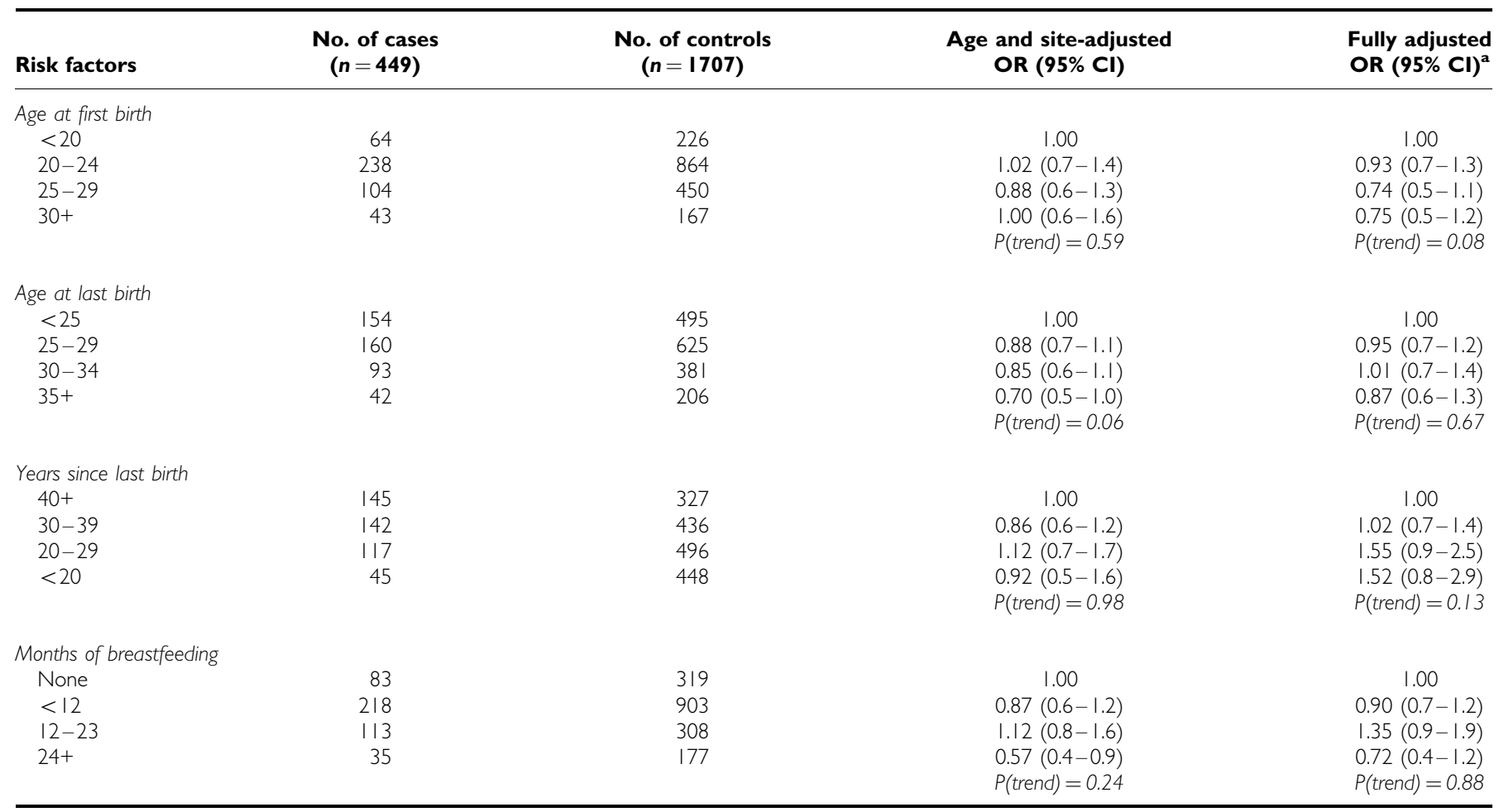

${ }^{a}$ Fully adjusted model includes age, study, site, years of education, age at menarche, number of full-term births, ever use of oral contraceptives, ever use of oral hormones, ever smoking, recent body mass index.

Table 4 Multivariate model of risk related to various correlated reproductive factors

\begin{tabular}{|c|c|c|c|c|}
\hline Risk factors & $\begin{array}{l}\text { No. of cases } \\
\quad(n=55 I)\end{array}$ & $\begin{array}{l}\text { No. of controls } \\
\quad(n=1925)\end{array}$ & $\begin{array}{c}\text { Age and site-adjusted } \\
\text { OR }(95 \% \mathrm{Cl})\end{array}$ & $\begin{array}{l}\text { Fully adjusted } \\
\text { OR }(95 \% \mathrm{CI})^{\mathrm{a}}\end{array}$ \\
\hline \multicolumn{5}{|c|}{ Number of full-term births } \\
\hline 0 & 102 & 218 & 1.00 & 1.00 \\
\hline 2 & 225 & 850 & $0.59(0.4-0.9)$ & $0.54(0.3-0.9)$ \\
\hline $3+$ & 53 & 313 & $0.33(0.2-0.6)$ & $0.30(0.2-0.5)$ \\
\hline \multicolumn{5}{|c|}{ Age at first birth ${ }^{b}$} \\
\hline $20-24$ & 238 & 864 & $0.88(0.6-1.2)$ & $0.87(0.6-1.2)$ \\
\hline $25-29$ & 104 & 450 & $0.69(0.5-1.0)$ & $0.67(0.4-1.0)$ \\
\hline $30+$ & 43 & 167 & $0.78(0.5-1.3)$ & $0.69(0.4-1.2)$ \\
\hline \multicolumn{5}{|c|}{ Age at last birth ${ }^{c}$} \\
\hline$<25$ & 59 & 230 & 1.00 & 1.00 \\
\hline $25-29$ & 115 & 452 & $1.25(0.8-1.8)$ & $1.22(0.8-1.8)$ \\
\hline $30-39$ & 142 & 436 & $0.84(0.6-1.2)$ & $0.91(0.6-1.3)$ \\
\hline $20-29$ & 117 & 496 & $1.00(0.6-1.6)$ & $1.10(0.7-1.8)$ \\
\hline$<20$ & 45 & 448 & $0.79(0.4-1.5)$ & $0.96(0.5-1.9)$ \\
\hline
\end{tabular}

${ }^{a}$ Fully adjusted model includes age, study site, years of education, age at menarche, ever use of oral contraceptives, ever use of oral hormones, ever smoking, recent body mass

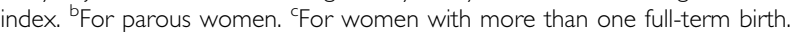

for presentation (Table 5). The inverse relation with parity was strongest among the youngest women. Thus, having three or more full-term births was associated with a $93 \%$ reduction in risk among the subjects 55 years of age or younger, as compared with only a $57 \%$ reduced risk among the older subjects. However, among the older subjects, both parity and age at first birth were related to risk, with those having a first birth at 30 years of age or older having an OR of 0.65 compared with those with a first birth at 20 or younger. There were no striking relationships with age at last birth or time since last birth. 
Table 5 Relationships of reproductive factors to endometrial cancer risk among parous women by varying ages at diagnosis

\begin{tabular}{|c|c|c|c|c|}
\hline & \multicolumn{2}{|c|}{ Study subjects $<55$ years of age ( 133 cases, 889 controls) } & \multicolumn{2}{|c|}{ Study subjects $55+$ years of age ( 418 cases, 1036 controls) } \\
\hline & $\begin{array}{l}\text { No. cases, } \\
\text { no. controls }\end{array}$ & $O R^{a}(95 \% \mathrm{Cl})$ & $\begin{array}{l}\text { No. cases, } \\
\text { no. controls }\end{array}$ & $O R^{a}(95 \% \mathrm{Cl})$ \\
\hline \multicolumn{5}{|c|}{ Number of full-term births } \\
\hline 0 & 39,99 & 1.00 (referent) & 63,119 & 1.00 (referent) \\
\hline I & 36,252 & $0.31(0.1-0.8)$ & 135,292 & $1.10(0.6-1.9)$ \\
\hline 2 & 51,411 & $0.17(0.05-0.5)$ & 174,439 & $0.77(0.4-1.3)$ \\
\hline \multicolumn{5}{|c|}{ Age at first birth } \\
\hline$<20$ & 8,93 & 1.00 (referent) & 56,133 & I.00 (referent) \\
\hline $20-24$ & 49,404 & $1.19(0.5-2.8)$ & 189,460 & $0.82(0.5-1.2)$ \\
\hline $25-29$ & 25,210 & $0.91(0.3-2.4)$ & 79,240 & $0.62(0.4-1.0)$ \\
\hline $30+$ & 12,83 & $0.94(0.3-3.0)$ & 31,84 & $0.65(0.3-1.2)$ \\
\hline \multicolumn{5}{|c|}{ Age at last birth ${ }^{b}$} \\
\hline \multicolumn{5}{|c|}{ Years since last birth } \\
\hline $25+$ & 28,170 & 1.00 (referent) & 334,832 & 1.00 (referent) \\
\hline $20-24$ & 26,201 & I.0। $(0.5-2.0)$ & 16,56 & $0.96(0.5-1.9)$ \\
\hline$<20$ & 40,419 & $1.17(0.5-2.8)$ & 5,29 & $0.59(0.2-1.8)$ \\
\hline
\end{tabular}

${ }^{a}$ Fully adjusted model includes age, study site, years of education, age at menarche, ever use of oral contraceptives, ever use of oral hormones, ever smoking, recent body mass index. ${ }^{b}$ For women with more than one full-term birth.

\section{DISCUSSION}

Similar to previous investigations (Brinton et al, 1992; Albrektsen et al, 1995; Hinkula et al, 2002), we found a substantially reduced risk of endometrial cancer associated with parity, with women having three or more full-term births being at a $70 \%$ lower risk than nulliparous women. To shed further light on the effects of reproduction, we focused our analyses on the timing of births, which proved to be challenging, given the high degree of correlation of ages at and intervals since a last birth (Albrektsen et al, 1999). We used a modelling approach (Heuch et al, 1999) that enabled combining data from parous and nulliparous women to separately evaluate effects of different parameters.

We were particularly interested in following up the observations of an inverse relationship of endometrial cancer risk with ages at (Kvale et al, 1988; Lesko et al, 1991; Parazzini et al, 1991, 1998; Lambe et al, 1999) and intervals since (Albrektsen et al, 1995; Parazzini et al, 1998) a last birth. Our results, like others (Shu et al, 1991; McPherson et al, 1996; Albrektsen et al, 1999), provide little support for these relationships. Although we had few women with short intervals since a last birth, we saw no effects even among our youngest study subjects, in whom we had the greatest power to assess relations. Most studies that have observed relationships with intervals since a last birth have observed trends persisting over many years rather than being restricted to the postpartum period, raising questions about the biologic credibility of the hypothesis of mechanical clearance of precancerous cells during delivery.

It is important to note that several studies that have emphasised the importance of timing of the last birth have been unable to fully account for other predictors of endometrial cancer (Kvale et al, 1988; Albrektsen et al, 1995; Lambe et al, 1999). This includes oral contraceptives, a recognised protective factor for endometrial cancer, and an exposure that would undoubtedly be more prevalent among subjects with late ages at first birth. This was not an important confounder in our study, given low rates of usage among Polish women, but other studies that have adjusted for oral contraceptives have shown a persistent effect of ages at last birth
(Lesko et al, 1991; Parazzini et al, 1998). It seems more likely that differing analytic techniques may explain study discrepancies, as an analysis that appropriately accounted for correlated variables also did not confirm an effect of late ages at a last birth (Albrektsen et al, 1999).

In contrast to the lack of association with ages at or intervals since a last birth, we observed that late ages at a first birth were associated with some risk reductions. This factor has not generally been regarded as a predictor of endometrial cancer risk (Pettersson et al, 1986; Lesko et al, 1991; Brinton et al, 1992; Parazzini et al, 1998; Xu et al, 2004), despite a number of studies that have demonstrated relatively strong associations (Kvale et al, 1988; Parslov et al, 2000; Hinkula et al, 2002; Wernli et al, 2006). Although it is widely accepted that multiparity may reduce endometrial cancer risk through changes in hormonal profiles, including lowered estradiol and increased sex hormone binding globulin levels (Chubak et al, 2004), underlying mechanisms for reduced risks associated with delayed ages at a first birth are less clear. This may relate to less frequent anovulation among women who can conceive at older ages (Escobedo et al, 1991; Modan et al, 1998). Future investigations should focus on hormonal changes associated with pregnancy, taking note of our findings as well as others (Pettersson et al, 1986; Albrektsen et al, 1995; Lambe et al, 1999) of stronger effects of multiparity among younger women.

The effects of infertility on endometrial cancer risk have been of considerable interest given that anovulatory menstrual cycles often reflect high exposure to oestrogens in the absence of sufficient progesterone. Elevated risks have been associated with delays in conception (Henderson et al, 1983; Shu et al, 1991), with one study showing a particularly high risk among nulliparous women (Brinton et al, 1992). Consistent with other investigations (Shu et al, 1991; McPherson et al, 1996), we found only a marginally elevated risk related to a physician diagnosis of infertility, with the relationship disappearing after adjustment for parity. The inconsistent findings across investigations may reflect varying definitions of infertility (Brinton et al, 2005). Given difficulties in obtaining accurate information from patients, future studies 
should focus on medically confirmed diagnoses, particularly those associated with hormonal alterations, such as polycystic ovarian disease, linked with uterine cancer risk elsewhere (Dahlgren et al, 1991; Escobedo et al, 1991; Modan et al, 1998; Pierpoint et al, 1998).

Our investigation also enabled evaluation of effects of shortterm pregnancies, including spontaneous and induced abortions. Although several studies have noted either reduced (Parazzini et al, 1998; Parslov et al, 2000) or increased (Shu et al, 1991; McPherson et al, 1996) risks, we found no substantial relationship with spontaneous abortions, in line with most other investigations (Brinton et al, 1992; Xu et al, 2004; Wernli et al, 2006). Previous studies assessing the effects of induced abortion on endometrial cancer risk have been inconsistent, possibly reflecting small numbers of exposed women. The majority have shown either no effect (Parazzini et al, 1991; Brinton et al, 1992; Wernli et al, 2006) or possibly some reduction in risk (Shu et al, 1991; Parazzini et al, 1998; Parslov et al, 2000). We had considerable power to evaluate effects of induced abortions, given that they have been legal in Poland for many years. We observed a slightly increased risk associated with the reporting of an induced abortion, consistent with one previous study (McPherson et al, 1996). However, we observed no further risk increase among women with multiple abortions, raising questions regarding the biologic credibility of the relation. Reporting bias (as seen in breast cancer studies) (Rookus and van Leeuwen, 1996; Bartholomew and Grimes, 1998; Tang et al, 2000), uncontrolled confounding, or chance may be involved.
Several investigations have suggested that women with extensive breastfeeding histories may be at reduced endometrial cancer risk (Rosenblatt and Thomas, 1995; Salazar-Martinez et al, 1999; Newcomb and Trentham-Dietz, 2000; Wernli et al, 2006), possibly from suppression of ovarian hormones (Petrakis et al, 1987). Although we initially observed reduced risk among subjects who breastfed for 2 or more years, this relation disappeared after adjustment for other risk factors. However, as in most studies in developing countries, we had few women who breastfed for extended periods of time.

In sum, this study confirmed that endometrial cancer is strongly related to parity. Using analytic techniques which overcome previous difficulties in assessing correlated reproductive variables, we found that late ages at a first birth also appeared to reduce risk, but that late ages at a last birth or extended intervals since a last birth were unrelated. Endometrial cancer risk did not appear to be substantially influenced by incomplete pregnancies, histories of infertility, or years of breastfeeding. Future investigations should focus on hormonal alterations underlying multiparity and late ages at a first birth in order to clarify processes involved in endometrial carcinogenesis.

\section{ACKNOWLEDGEMENTS}

This research was supported by funds from the intramural program of the National Cancer Institute, National Institutes of Health.

\section{REFERENCES}

Albrektsen G, Heuch I, Kvale G (1999) Joint effects on cancer risk of age at childbirth, time since birth and attained age: circumventing the problem of collinearity. Stat Med 18: $1261-1277$

Albrektsen G, Heuch I, Tretli S, Kvale G (1995) Is the risk of cancer of the corpus uteri reduced by a recent pregnancy. A prospective study of 765756 Norwegian women. Int J Cancer 61: 485-490

Bartholomew LL, Grimes DA (1998) The alleged association between induced abortion and risk of breast cancer: biology or bias? Obstet Gynecol Surv 53: $708-714$

Brinton LA, Berman ML, Mortel R, Twiggs LB, Barrett RJ, Wilbanks GD, Lannom L, Hoover RN (1992) Reproductive, menstrual, and medical risk factors for endometrial cancer: results from a case-control study. Am J Obstet Gynecol 167: 1317-1325

Brinton LA, Westhoff CL, Scoccia B, Lamb EJ, Althuis MD, Mabie JE, Moghissi KS (2005) Causes of infertility as predictors of subsequent cancer risk. Epidemiology 16: 500-507

Chubak J, Tworoger SS, Yasui Y, Ulrich CM, Stanczyk FZ, McTiernan A (2004) Associations between reproductive and menstrual factors and postmenopausal sex hormone concentrations. Cancer Epidemiol Biomarkers Prev 13: 1296-1301

Dahlgren E, Friberg LG, Johansson S, Lindstrom B, Oden A, Samsioe G, Janson PO (1991) Endometrial carcinoma; ovarian dysfunction - a risk factor in young women. Eur J Obstet Gynecol Reprod Biol 41: 143-150

Escobedo LG, Lee NC, Peterson HB, Wingo PA (1991) Infertility-associated endometrial cancer risk may be limited to specific subgroups of infertile women. Obstet Gynecol 77: 124-128

Henderson BE, Casagrande JT, Pike MC, Mack T, Rosario I, Duke A (1983) The epidemiology of endometrial cancer in young women. Br J Cancer 47: $749-756$

Heuch I, Albrektsen G, Kvale G (1999) Modeling effects of age at and time since delivery on subsequent risk of cancer. Epidemiology 10: $739-746$

Hinkula M, Pukkala E, Kyyronen P, Kauppila A (2002) Grand multiparity and incidence of endometrial cancer: a population-based study in Finland. Int J Cancer 98: 912-915

Kaaks R, Lukanova A, Kurzer MS (2002) Obesity, endogenous hormones, and endometrial cancer risk: a synthetic review. Cancer Epidemiol Biomarkers Prev 11: 1531 - 1543
Kvale G, Heuch I, Nilssen S (1991) Reproductive factors and cancers of the breast and genital organs - are the different cancer sites similarly affected? Cancer Detect Prev 15: 369-377

Kvale G, Heuch I, Ursin G (1988) Reproductive factors and risk of cancer of the uterine corpus: a prospective study. Cancer Res 48: 6217-6221

Lambe M, Wuu J, Weiderpass E, Hsieh CC (1999) Childbearing at older age and endometrial cancer risk (Sweden). Cancer Causes Control 10: $43-49$

Lesko SM, Rosenberg L, Kaufman DW, Stolley P, Warshauer ME, Lewis Jr JL, Shapiro S (1991) Endometrial cancer and age at last delivery: evidence for an association. Am J Epidemiol 133: 554-559

McPherson CP, Sellers TA, Potter JD, Bostick RM, Folsom AR (1996) Reproductive factors and risk of endometrial cancer. The Iowa Women's Health Study. Am J Epidemiol 143: 1195-1202

Modan B, Ron E, Lerner-Geva L, Blumstein T, Menczer J, Rabinovici J, Oelsner G, Freedman L, Mashiach S, Lunenfeld B (1998) Cancer incidence in a cohort of infertile women. Am J Epidemiol 147: $1038-1042$

Newcomb PA, Trentham-Dietz A (2000) Breast feeding practices in relation to endometrial cancer risk, USA. Cancer Causes Control 11: $663-667$

Parazzini F, La Vecchia C, Negri E, Fedele L, Balotta F (1991) Reproductive factors and risk of endometrial cancer. Am J Obstet Gynecol 164: $522-527$

Parazzini F, Negri E, La Vecchia C, Benzi G, Chiaffarino F, Polatti A, Francheschi S (1998) Role of reproductive factors on the risk of endometrial cancer. Int J Cancer 76: 784-786

Parslov M, Lidegaard O, Klintorp S, Pedersen B, Jonsson L, Eriksen PS, Ottesen B (2000) Risk factors among young women with endometrial cancer: a Danish case-control study. Am J Obstet Gynecol 182: $23-29$

Petrakis NL, Wrensch MR, Ernster VL, Miike R, Murai J, Simberg N, Siiteri PK (1987) Influence of pregnancy and lactation on serum and breast fluid estrogen levels: implications for breast cancer risk. Int J Cancer 40: 587-591

Pettersson B, Adami HO, Bergstrom R, Johansson ED (1986) Menstruation span - a time-limited risk factor for endometrial carcinoma. Acta Obstet Gynecol Scand 65: 247-255 
Pierpoint T, McKeigue PM, Isaacs AJ, Wild SH, Jacobs HS (1998) Mortality of women with polycystic ovary syndrome at long-term follow-up. J Clin Epidemiol 51: $581-586$

Rookus MA, van Leeuwen FE (1996) Induced abortion and risk for breast cancer: reporting (recall) bias in a Dutch case-control study. J Nat Cancer Inst 88: $1759-1764$

Rosenblatt KA, Thomas DB (1995) Prolonged lactation and endometrial cancer. WHO Collaborative Study of Neoplasia and Steroid Contraceptives. Int J Epidemiol 24: 499-503

Salazar-Martinez E, Lazcano-Ponce EC, Gonzalez Lira-Lira G, Escudero-De los RP, Salmeron-Castro J, Hernandez-Avila M (1999) Reproductive factors of ovarian and endometrial cancer risk in a high fertility population in Mexico. Cancer Res 59: 3658-3662
Shu XO, Brinton LA, Zheng W, Gao YT, Fan J, Fraumeni Jr JF (1991) A population-based case-control study of endometrial cancer in Shanghai, China. Int J Cancer 49: $38-43$

Tang MT, Weiss NS, Daling JR, Malone KE (2000) Case-control differences in the reliability of reporting a history of induced abortion. Am J Epidemiol 151: 1139-1143

Wernli KJ, Ray RM, Gao DL, De Roos AJ, Checkoway H, Thomas DB (2006) Menstrual and reproductive factors in relation to risk of endometrial cancer in Chinese women. Cancer Causes Control 17: 949-955

Xu WH, Xiang YB, Ruan ZX, Zheng W, Cheng JR, Dai Q, Gao YT, Shu XO (2004) Menstrual and reproductive factors and endometrial cancer risk: Results from a population-based case - control study in urban Shanghai. Int J Cancer 108: 613-619 